\title{
HEC influence on cement hydration measured by conductometry
}

\author{
J. Pourchez ${ }^{1 *}-$ P. Grosseau ${ }^{1}-$ R. Guyonnet ${ }^{1}-$ B. Ruot $^{2}$
}

${ }^{1}$ École Nationale Supérieure des Mines de Saint-Étienne (ENSMSE-SPIN)

LPMG: process in granular media laboratory CNRS UMR 5148

158, cours Fauriel 42023 Saint-Étienne cedex 2 - France

${ }^{2}$ Scientific and Technical Centre for Building (CSTB)

84, avenue Jean Jaurès - Champs-sur-Marne - 77447 Marne-la-Vallée cedex 2 - France

* Corresponding author: Tel: (+33) 4774266 86; Fax: (+33) 4774996 94;

E-mail address: pourchez@emse.fr 


\begin{abstract}
.
Cellulose ethers are of universal use in factory-made mortars, though their influences on mortar properties at a molecular scale are poorly understood. Recent studies dealt with the influence of hydroxyethylmethyl cellulose (HEMC) and hydroxypropylmethyl cellulose (HPMC) molecular parameters on cement hydration. It was concluded that the degree of substitution is the most relevant factor on cement hydration kinetics, contrary to the molecular weight. Nevertheless, the major role played by the substitution degree has not been verified for other types of cellulose ethers such as hydroxyethyl cellulose (HEC), which generally possesses a higher hydration retarding capacity compared to HPMC and HEMC. In this frame, a study of the impact of HEC molecular parameters on cement hydration was performed. A negligible influence of the molecular weight was observed. Moreover, the results emphasize that the hydroxyethyl group content mainly determines the delay of cement hydration.
\end{abstract}

Keywords: Cellulose ethers; Cement hydration; Retardation; Kinetics; Conductometry

\title{
1. Introduction
}

Cellulose ethers are commonly introduced into industrial mortar formulations in order to improve workability of the fresh material and adherence to the substrate. Moreover, these macromolecules cause a significant increase of the water retention capacity and the viscosity of the paste. However, cellulose ethers may also induce a retardation of the cement hydration. So, the major drawback of cellulose ethers in mortar formulation is the uncontrolled and poorly understood hydration delay. Therefore, the knowledge of the molecular parameters that enable to control and to predict the hydration kinetics of cement modified with cellulose ethers represents a great benefit for the mortar manufacturers. As a general rule, one of the 
assumptions usually proposed to explain the retardation capacity of cellulose ethers consists in considering a decrease of the ion mobility [1]. As a result, the effect of cellulose ethers is attributed to the increased viscosity of the water, which imparts the movement of ions, decreasing the dissolution rate of anhydrous phases and the precipitation of hydrates. Nevertheless, recent insights concerning interactions between cement and cellulose ethers are in contradiction with this hypothesis of a diffusion barrier. Actually, using range of wellcharacterized hydroxypropylmethyl cellulose (HPMC) and hydroxyethylmethyl cellulose (HEMC) with different investigation tools to follow cement hydration, different studies [2,3] come to similar results: the degree of substitution (DS) is the key parameter which influences the hydration delay.

Fast in situ measurements of cement and pure phases paste by synchrotron X-ray diffraction (XRD) were performed by Weyer et al. so as to determine the impact of cellulose ethers on cement hydration [2]. This suitable method allows on-line monitoring due to high time resolution. Cement and pure phase experiments showed that the portlandite (noted $\mathrm{CH}$ ) precipitation is strongly and DS-specifically inhibited. Finally, hydration kinetics observed by synchrotron XRD allowed to conclude that the lower the DS, the stronger the delay of $\mathrm{C}_{2} \mathrm{~S} / \mathrm{C}_{3} \mathrm{~S}$ hydration. The molecular parameters which mainly influence the retarding effect of HPMCs and HEMCs were also identified by Pourchez et al. [3]. The impact of the weightaverage molecular weight $\left(M_{\mathrm{w}}\right)$ was determined thanks to cellulose ether samples having identical chemical structure and differing only by their molecular weights. The impact of the substitution degree was evaluated with molecules having identical molecular weight and only differ by their hydroxyethyl, hydroxypropyl or methoxyl contents. The influence of these parameters on hydration delay was assessed by conductometric measurements in water and limewater suspensions. A minor influence of the molecular weight and of the hydroxypropyl or the hydroxyethyl content was observed. On the contrary, the methoxyl content appeared as 
the key parameter of the hydration delay mechanism since the $\mathrm{CH}$ precipitation increased with decreasing methoxyl values.

In Europe, the most widespread cellulose ethers used in building materials are HEMCs and HPMCs. Hydroxyethyl cellulose (HEC) is principally interesting for fundamental studies because of its more simple chemical structure. Moreover, HECs are also frequently introduced in dry-set mortar production in South America [1,4,5]. Using the same experimental procedures as the previous paper [3], the impact on hydration retardation of the HEC molecular parameters is examined.

\section{Mineral and organic compounds}

The investigated binder was a CEM I 52.5R CE CP2 NF type cement according to NF EN 197-1 standard. Its chemical and phase compositions are given in Table 1. The chemical structure of HEC is entirely determined by two parameters i.e. the molecular weight $\left(M_{\mathrm{w}}\right)$ and the hydroxyethyl content (\% EOOH) (Fig. 1). The panel of 17 well-characterized HECs was broad enough to allow the comparison of molecules which differ by only one parameter. The molecular weight distribution was performed by Size Exclusion Chromatography (SEC) and the substitution degree was investigated by Near Infra-Red spectroscopy (NIR). All details concerning SEC and NIR protocols were previously described [3].

\section{Hydration delay characterization}

Conductometry is a powerful tool for monitoring the hydration kinetics. This technique provides rather detailed information on the different steps of the hydration reaction $[3,6,7]$. In particular, Damidot showed that the initial portlandite precipitation was represented by an electrical conductivity drop together with an endothermic peak [7]. Conductometric experiments were performed in water or limewater suspension, with a high liquid to solid (L/S) weight ratio (equal to 20 ) and an admixture to cement (A/C) weight ratio of $2 \%$. The 
apparatus was thermostated at $25{ }^{\circ} \mathrm{C}$ and the experiments were carried out in triplicate. The quantification of the hydration delay uses the $\mathrm{CH}$ precipitation time as a benchmark, which corresponds to a drop of conductometry. This methodology was successfully applied to classify the relative retardation capacity of HPMCs and HEMCs on cement hydration [3].

The $\mathrm{CH}$ precipitation time is very sensitive to the water to cement ratio in the conductometric test, and thus only indirectly related to the actual hydration degree under more realistic conditions comparatively to a cement paste. Actually, conductometry is not a direct measure of the degree of hydration of the cement, but it is a convenient comparative method as long as the relative concentrations of all ingredients are kept constant and only one variable is changed at a time (in this case, a perfectly known parameter of the admixture).

\section{Results}

First of all, it is obvious that the retarding capacity of the HEC samples is very important (Fig. 2). Even though the hydration delay on the portlandite precipitation induced by HPMCs and HEMCs was always inferior to two hours (for $\mathrm{A} / \mathrm{C}=2 \%$ in limewater) [1], the delay induced by HECs is always higher than 2 hours (in the same experimental conditions). The highest retardation capacity reaches 13 hours for the HEC molecule named S1. Moreover, according to the previous study on HPMCs and HEMCs, hydration retardation in limewater is higher than the one in water.

\subsection{Influence of the hydroxyethyl content on portlandite precipitation delay}

The effect of \% EOOH was investigated with three pairs of appropriate admixtures reported in Table 2. To facilitate the visualization of this important delay, we expressed the retardation by means of increasing of portlandite precipitation time in percentage. The results are illustrated in Fig. 3. Clearly, the portlandite precipitation delay increases with decreasing \% $\mathrm{EOOH}$. The same tendency can be observed in aqueous system and in limewater suspension. 
For example, for a given molecular weight of 750000 daltons, the substantial difference of retardation reaches $150 \%$ (approximately 400 minutes) between $\mathrm{S} 1$ at $38.5 \%$ of $\mathrm{EOOH}$ and S2 at $48.5 \%$ of EOOH. Only a variation of the substitution degree seems to be sufficient to induce a great difference in portlandite precipitation retardation.

\subsection{Influence of the molecular weight on portlandite precipitation delay}

Two ranges of 7 and 6 HECs having various $M_{\mathrm{w}}$ but identical substitution degree were used (Table 3). The first panel (named N) at $56 \%$ of EOOH shows a delay always constant (Fig. 4). As a matter of fact, whatever the molecular weight varying between 175000 and 1525000 daltons, the increasing of portlandite precipitation time reaches $50 \%$ for conductometric measurements in aqueous system. In limewater suspension, the increasing reaches $75 \%$. The second panel (named $\mathrm{H}$ ) at $48.5 \%$ reveals a quite different hydration delay versus $M_{\mathrm{w}}$ behaviour (Fig. 5). Even if the hydration delay seems to be constant for the higher $M_{\mathrm{w}}$ molecules, H1 sample which has a molecular weight of 175000 daltons, leads to an important retardation of $250 \%$ in limewater suspension. Nevertheless, when Fig. 3, Fig. 4 and Fig. 5 are compared, the negligible impact of the molecular weight on cement hydration is obvious.

Nevertheless, H1 sample has a particular behaviour which is still not perfectly understood. Maybe, this lower $M_{\mathrm{w}}$ molecule with a high retardation capacity of precipitation retardation is a sign indicating that $M_{\mathrm{w}}$ and the substitution degree are not independent parameters concerning the hydration delay mechanism. This low $M_{\mathrm{w}}$ molecule might have an impact on hydration kinetics (for a given and specific value of DS), because this structure favours key phenomenon of the hydration delay mechanism such as adsorption or degradation of cellulose ethers in alkaline media. Future fundamental researches on the interactions between cement and cellulose ether would allow proposing a mechanism which could explain these experimental observations on the molecular parameters influence. 


\section{Conclusions}

The HEC molecular parameters have the same impact on cement hydration as HPMC and HEMC ones. The degree of substitution DS represents the key parameter on the portlandite precipitation delay; the negligible impact of the molecular weight is again verified. Cellulose ethers may therefore be designed to control such a phenomenon. Furthermore, conductometric experiments were performed in very diluted suspension; in that case, the concentration of polymer in solution was very low compared to a cement paste modified with cellulose ethers. Although the concentration of polymer was not sufficient to induce great viscosity change, we observed in diluted suspension the same order of magnitude of hydration delay than in cement paste. Therefore, the link between viscosity and retardation is not obvious and the assumption of a diffusion barrier induced by the high viscous solution of cellulose ethers is not the most relevant.

\section{Acknowledgements}

The authors would like to acknowledge the financial support of the international CEReM network (consortium for study and research on mortars - http://cerem.cstb.fr), and many helpful conversations with industrial and academic partners. 


\section{References}

[1] D.A. SILVA, H.R. ROMAN, V.M. JOHN, Effects of EVA and HEC polymers on the Portland cement hydration. Proceeding of the $11^{\text {th }}$ International Congress on Polymers in Concrete (2004); 91-97.

[2] H.J. WEYER, I. MULLER, B. SCHMITT. D. BOSBACH, A. PUTNIS, Time-resolved monitoring of cement hydration: Influence of cellulose ethers on hydration kinetics. Nuclear instrument and methods in physics research Section B 238 (2005) 102-106.

[3] J. POURCHEZ, A. PESCHARD, P. GROSSEAU, B. GUILHOT, R. GUYONNET, F. VALLEE, HPMC and HEMC influence on cement hydration, Cem. Concr. Res. 36 (2006) 288-294.

[4] D.A. SILVA, V.M. JOHN, J.L.D RIBEIRO, H.R. ROMAN, Pore size distribution of hydrated cement pastes modified with polymers, Cem. Concr. Res. 31 (8) (2001) 1319-1329.

[5] N.K. SINGH, P.C. MISHRA, V.K. SINGH, K.K. NARANG, Effect of hydroxyethyl cellulose and oxalic acid on the properties of cement. Cem. Concr. Res. 33 (9) (1997) $1177-$ 1184.

[6] A. NONAT, J.C. MUTIN, X. LECOCQ, S.P. JIANG, Physico-chemical parameters determining hydration and particle interactions during the setting of silicate cements, Solid State Ionics 101-103 (1997) 923-930.

[7] D. DAMIDOT, A. NONAT, P. BARRET, Kinetics of tricalcium silicate hydration in diluted suspensions by microcalorimetric measurements, J. Am. Ceram. Soc. 73 (11) (1990) 
3319-3322. 
Table 1

\begin{tabular}{|c|c|c|c|c|}
\hline \multicolumn{2}{|c|}{$\begin{array}{c}\text { Chemical composition (\% } \\
\text { wt) }\end{array}$} & \multicolumn{3}{|c|}{ Phase composition (\% wt) } \\
\hline Oxides & $\mathrm{XRF}$ analysis & Phases & $\begin{array}{c}\text { XRF analysis and } \\
\text { Bogue }\end{array}$ & $\begin{array}{l}\text { XRD analysis and } \\
\text { Rietveld }\end{array}$ \\
\hline $\mathrm{CaO}$ & $67.11 \%$ & $\mathrm{C}_{3} \mathrm{~S}$ & $67.5 \%$ & $69.4 \%$ \\
\hline $\mathrm{SiO}_{2}$ & $21.18 \%$ & $\mathrm{C}_{2} \mathrm{~S}$ & $9.8 \%$ & $9.3 \%$ \\
\hline $\mathrm{Al}_{2} \mathrm{O}_{3}$ & $4.29 \%$ & $\mathrm{C}_{3} \mathrm{~A}$ & $8.3 \%$ & $8.3 \%$ \\
\hline $\mathrm{SO}_{3}$ & $4.65 \%$ & $\mathrm{C}_{4} \mathrm{AF}$ & $5.5 \%$ & $3.1 \%$ \\
\hline $\mathrm{Fe}_{2} \mathrm{O}_{3}$ & $1.82 \%$ & Gypsum & $4.65 \%$ & $3.6 \%$ \\
\hline $\mathrm{MgO}$ & $0.58 \%$ & $\mathrm{CaCO}_{3}$ & - & $4.9 \%$ \\
\hline $\mathrm{TiO}_{2}$ & $0.21 \%$ & Anhydrite & - & $1.2 \%$ \\
\hline $\mathrm{P}_{2} \mathrm{O}_{5}$ & $0.23 \%$ & Quartz & - & $0.2 \%$ \\
\hline $\mathrm{Na}_{2} \mathrm{O}$ & $0.19 \%$ & & & \\
\hline $\mathrm{K}_{2} \mathrm{O}$ & $0.11 \%$ & & & \\
\hline
\end{tabular}


Table 1. Chemical and phase composition of the investigated cement.

$$
\text { J. Pourchez }{ }^{1 *}-\text { P. Grosseau }{ }^{1}-\text { R. Guyonnet }{ }^{1}-\text { B. } \text { Ruot }^{2}
$$


Fig. 1

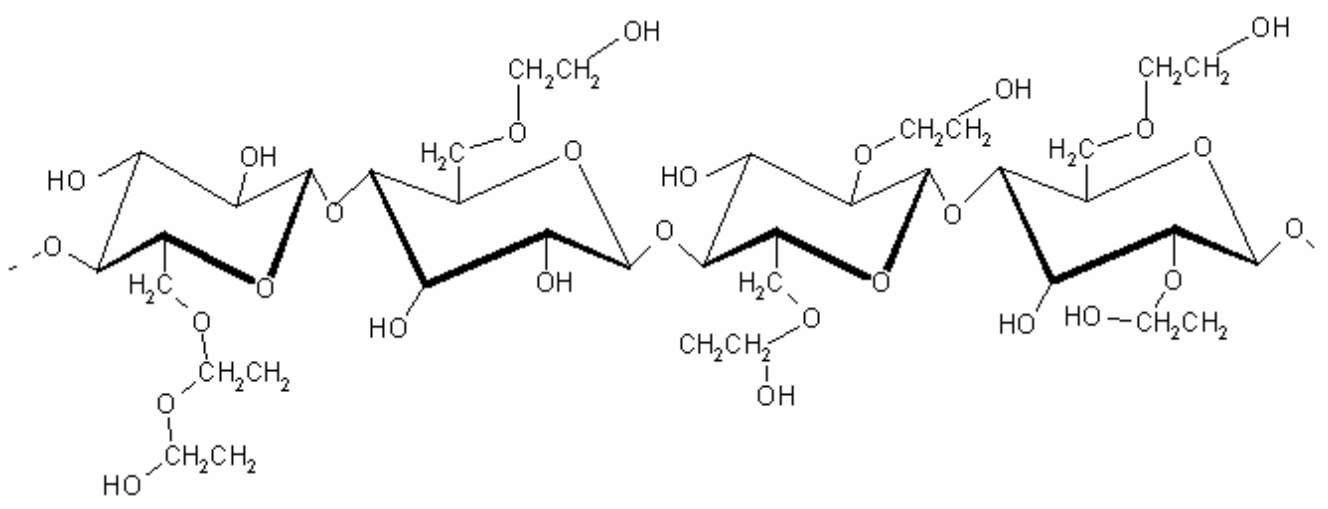


Figure 1. Structure of HEC molecule

J. Pourchez ${ }^{1 *}-$ P. Grosseau ${ }^{1}-$ R. Guyonnet ${ }^{1}-$ B. Ruot ${ }^{2}$ 
Fig. 2

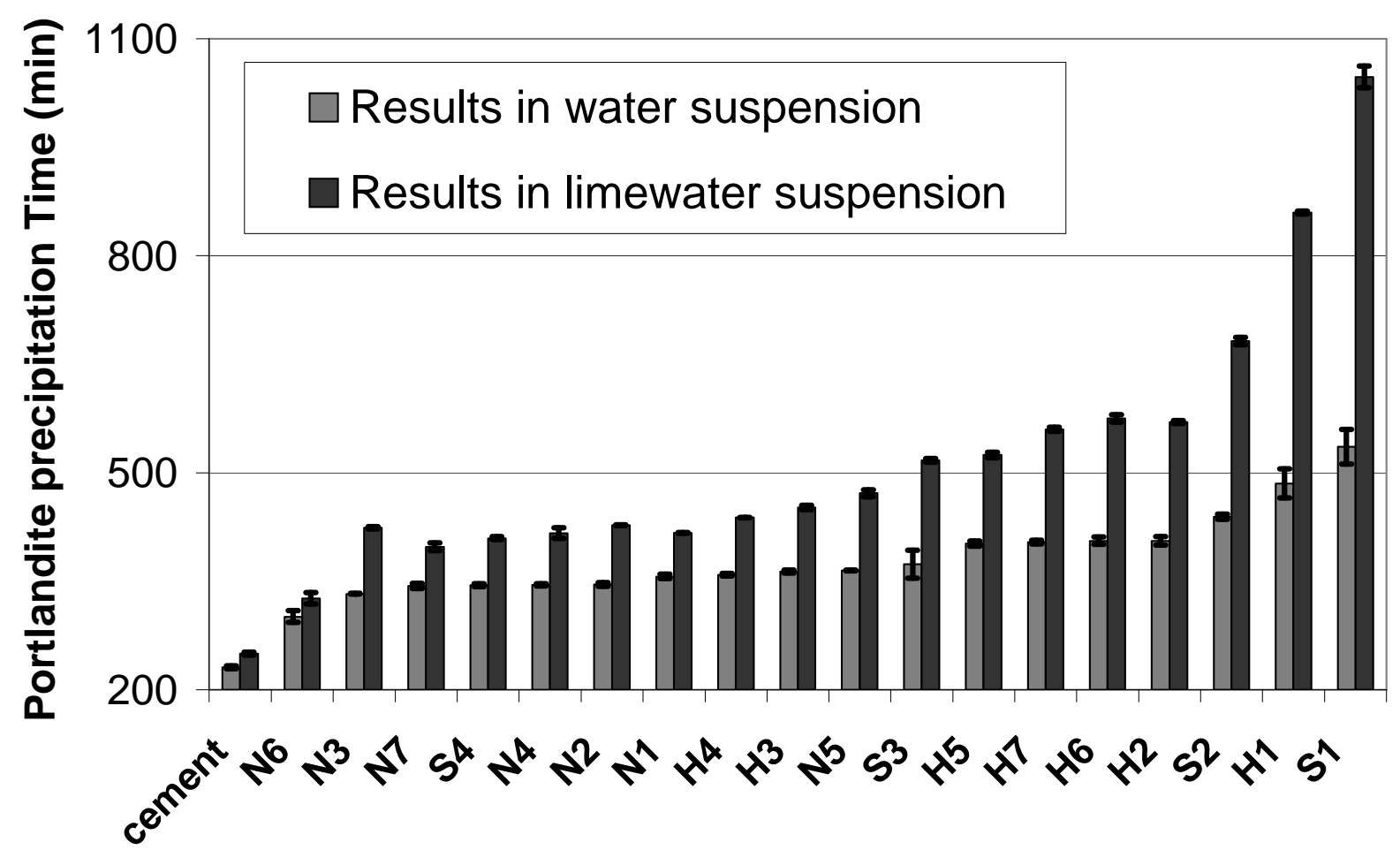


Figure 2. Portlandite precipitation delay in aqueous and limewater system (L/S=20).

J. Pourchez ${ }^{1 *}-$ P. Grosseau ${ }^{1}-$ R. Guyonnet ${ }^{1}-$ B. Ruot ${ }^{2}$ 
Table 2

\begin{tabular}{ccccccc}
\hline & H1 & N1 & S1 & S2 & S3 & S4 \\
\hline$M_{\mathbf{w}}(\times 1000$ Daltons $)$ & 175 & 175 & 750 & 750 & 920 & 920 \\
$\begin{array}{c}\text { Hydroxyethyl group } \\
(\% \text { EOOH })\end{array}$ & 48.5 & 56 & 38.5 & 48.5 & 55 & 60.5 \\
\hline
\end{tabular}


Table 2. Ranges of HEC to investigate the impact of the molecular weight.

$$
\text { J. Pourchez }{ }^{1 *} \text { - P. Grosseau }{ }^{1}-\text { R. Guyonnet }{ }^{1}-\text { B. Ruot }{ }^{2}
$$


Fig. 3

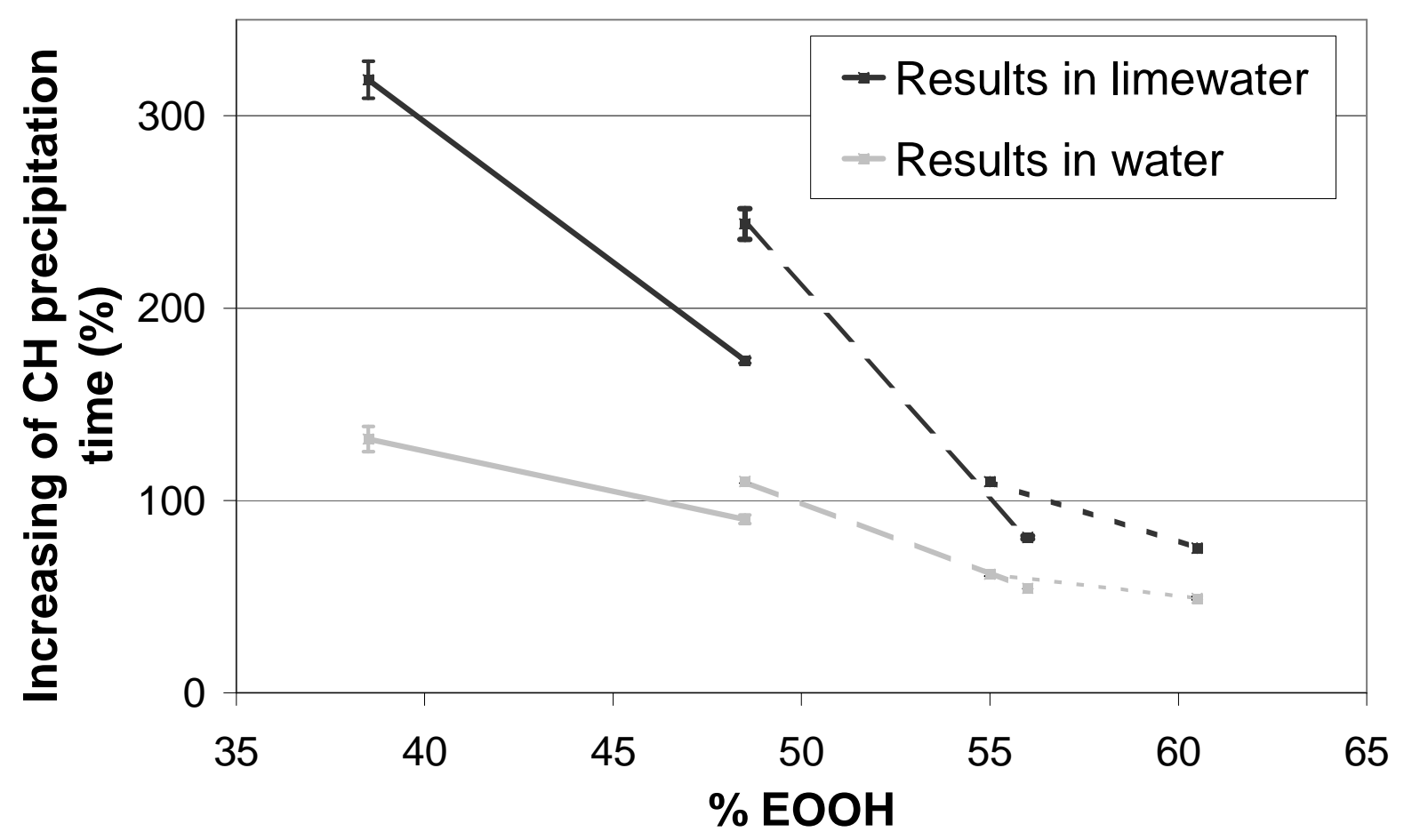


Figure 3. Influence of $\% \mathrm{EOOH}$ on portlandite precipitation delay

J. Pourchez ${ }^{1 *}-$ P. Grosseau ${ }^{1}-$ R. Guyonnet ${ }^{1}-$ B. Ruot ${ }^{2}$ 
Table 3

\begin{tabular}{|c|c|c|c|c|c|c|c|}
\hline & H1 & H2 & H3 & H4 & H5 & H6 & H7 \\
\hline$M_{\mathrm{w}}(\times 1000$ Daltons $)$ & 175 & 250 & 1300 & 1350 & 1400 & 1475 & 1525 \\
\hline \multirow[t]{2}{*}{$\begin{array}{c}\text { Hydroxyethyl group } \\
(\% \text { EOOH })\end{array}$} & 48.5 & 48.5 & 48.5 & 48.5 & 48.5 & 48.5 & 48.5 \\
\hline & N1 & $\mathbf{N} 2$ & N4 & N7 & N3 & N6 & \\
\hline$M_{\mathrm{w}}(\times 1000$ Daltons $)$ & 175 & 600 & 900 & 1335 & 2600 & 2775 & \\
\hline $\begin{array}{c}\text { Hydroxyethyl group } \\
(\% \text { EOOH })\end{array}$ & 56 & 56 & 56 & 56 & 56 & 56 & \\
\hline
\end{tabular}


Table 3. Ranges of HEC to investigate the impact of the hydroxyethyl content.

$$
\text { J. Pourchez }{ }^{1 *}-\text { P. Grosseau }{ }^{1}-\text { R. Guyonnet }{ }^{1}-\text { B. Ruot }{ }^{2}
$$


Fig. 4

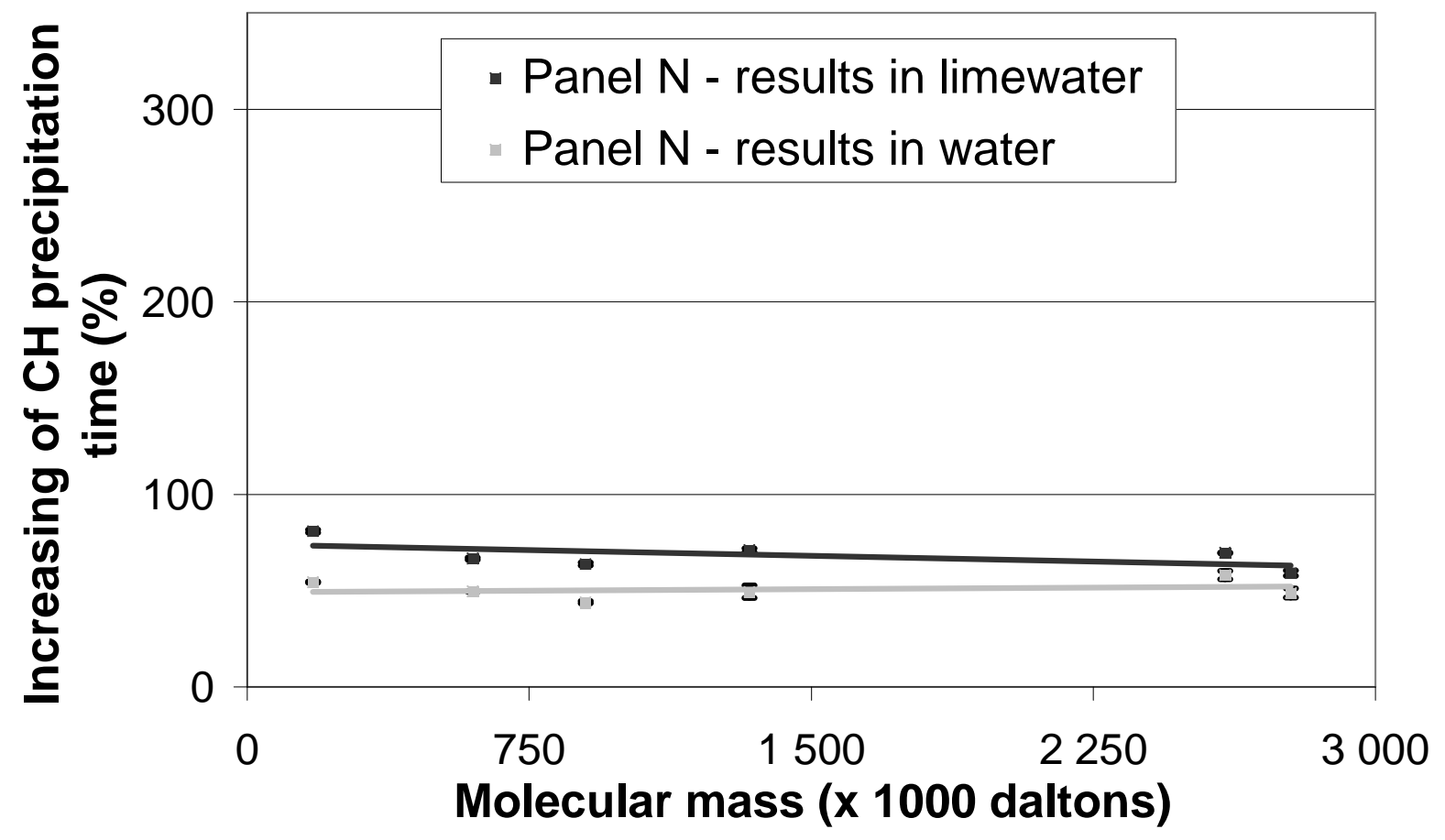


Figure 4. Influence of $M_{\mathrm{w}}$ on portlandite precipitation delay (range $\mathrm{N}$ )

J. Pourchez ${ }^{1 *}-$ P. Grosseau ${ }^{1}-$ R. Guyonnet ${ }^{1}-$ B. Ruot $^{2}$ 
Fig. 5

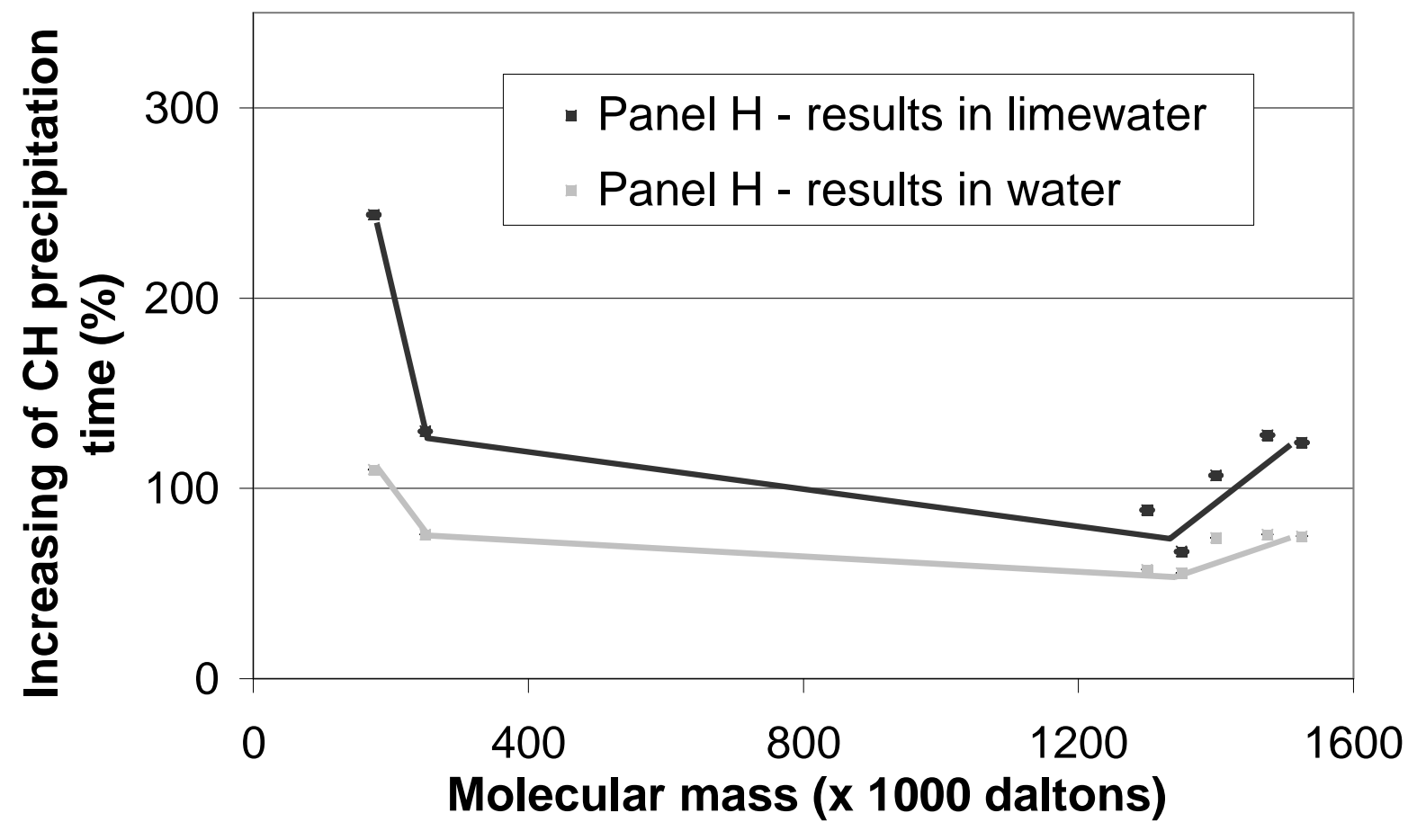


Figure 5. Influence of $M_{\mathrm{w}}$ on portlandite precipitation delay (range H)

J. Pourchez ${ }^{1 *}-$ P. Grosseau ${ }^{1}-$ R. Guyonnet ${ }^{1}-$ B. Ruot $^{2}$ 


\section{Captions}

Table 1 Chemical and phase composition of the investigated cement.

Figure 1 Structure of HEC molecule.

Figure 2 Portlandite precipitation delay in aqueous and limewater system (L/S=20).

Table 2 Ranges of HEC to investigate the impact of the molecular weight.

Figure 3 Influence of $\% \mathrm{EOOH}$ on portlandite precipitation delay.

Table 3 Ranges of HEC to investigate the impact of the hydroxyethyl content.

Figure 4 Influence of $M_{\mathrm{w}}$ on portlandite precipitation delay (range N).

Figure 5 Influence of $M_{\mathrm{w}}$ on portlandite precipitation delay (range $\mathrm{H}$ ). 